\title{
From Self-care for Healthy People to Self-management for Cancer Patients with Cancer Portals
}

\author{
Zahra Azadmanjir, Reza Safdari*, Marjan Ghazisaeidi
}

\begin{abstract}
Self-care to prevent cancer and self-management to cope with the disease are two discrete effective mechanisms for improving of control and management of neoplasia. Both them have certain strategies and practices. Often the two are used interchangeably despite their different approaches. Strategies of self-care usually refer to prevention at different levels include primary, secondary and tertiary. In contrast, strategies of self-management are related to management and alleviation of unpleasant cancer-related symptoms and treatment-related side effects for improving the quality of life of cancer survivors. Successful promoting of self-care and self-management strategies need people and survivor empowerment. Within this context, innovative approaches open a new window. In this paper after a brief review of related strategies and practices, we provide an explanation of how cancer portals may play an important role in the empowerment process and what are key potentials for implementing of selfcare and self-management strategies for cancer.
\end{abstract}

Keywords: Self-care - self-management - cancer - portal - symptom management - prevention

Asian Pac J Cancer Prev, 16 (4), 1321-1325

\section{Introduction}

Cancer is one type of chronic diseases that has an increasing prevalence in the worldwide. According to latest world statistics about cancer there were 32.6 million people (over the age of 15 years) who had cancer in 2012 and this disease diagnosed in the previous five years (IARC, 2013). From this number, 13 million were in Asia (GLOBOCAN, 2014a). In addition, it is expected that annual cancer cases will rise from 14 million in 2012 to 2022(IARC, 2013). In addition, in Asia has been predicted the number of new cases will increase to 7.1 million by the 2020 (Yoo, 2010). Both cancer burden and care complexity are substantial. Beyond the malignancy problem, cancer patients experience many distressing and unpleasant symptoms or consequences during their illness (Shoemaker et al., 2011). Studies have depicted that, fatigue, disturbed sleep and subsequent daytime sleepiness, pain, dry mouth, anorexia, nausea and vomiting are common cancer-related or treatment-related symptoms in cancer patients (Shoemaker et al., 2011; Skerman et al., 2012; Cleeland et al., 2013).

Therefore, from the one hand, countries should be focusing on strategies of primary prevention and secondary prevention that is early detection. More efficient the strategies include raising public awareness about cancer and its risk factors, lifestyle changes, public awareness about screening programs (Yoo, 2010) and also, education for self-examination for breast cancer (Loh and
Chew, 2011; Yoo et al., 2012), which is most common cancer between women (36.4\%) in the worldwide(Benson and Jatoi, 2012; Globocan, 2014b). On the other hand, countries should use effective approaches to improve cancer prevention and care.

\section{Self-care and Self-management Concepts in Cancer Prevention and Care}

The continuum of care in cancer disease has been defined in prevention, early detection/screening, diagnosis, treatment, survivorship or end-of-life care (Hewitt et al., 2005; Spinks et al., 2014). However, self-care and selfmanagement strategies can be included in the continuum to improve the disease control and management outcomes. Scholars have the opinion that cancer problem not only requires professional care, but requires self-care and selfmanagement too (Oluka et al., 2014).

There are different definitions of self-care. World Health Organization presented the following definition (WHO, 2009): "Self-care is the ability of individuals, families and communities to promote health, prevent disease, and maintain health and to cope with illness and disability with or without the support of a healthcare provider".

Webber and colleagues concluded with a review of some existing definitions that all of those definitions are aimed primarily at healthy people and refer to prevention of disease (Webber et al., 2013). 
Although some of the scholars self-management defined as a component of self-care for both healthy people and patients (Ageing, 2009; McCorkle et al., 2011; Oluka et al., 2014), others only applied this term for describing of managing disease-related symptoms, treatment-related consequents and long-term the impact of illness in patients with chronic condition by themselves (Loh et al., 2010; Loh et al., 2011a; Lovell et al., 2014). The first group has an opinion that self-management is an effective paradigm across the prevention spectrum moreover, that represents a promising strategy for treating (Grady and Gough, 2014).

We use from Barlow suggestion for interpreting selfcare and self-management concepts. According to Barlow, self-care is a preventative strategy and performed by healthy people. Nevertheless, self-management defined as daily tasks a patient should undertake to control or reduce the impact of a chronic disease and its consequences (Barlow et al., 2002). About cancer, it is possible that some self-care practices, for example lifestyle changes, be available in cancer self-management for its control, but it is better that the self-management term used to describe it.

Within this context, innovative approaches open a new window for effective implementing self-care and selfmanagement strategies (Jung, 2013). A new technology, which can useful, is the using of web-based and mobilebased portals. The authors after a brief review of related strategies and practices, explain this fact that how cancer specialized portals affected self-care and self-management of cancer.

\section{Cancer Self-care and Self-management Strategies}

\section{Self-care strategies against cancer}

As mentioned before, self-care more refers to prevention. Therefore, related strategies are also relevant to cancer prevention in different levels. Person's awareness raising on cancer is a preliminary strategy for self-care against cancer. Because, people who have insufficient awareness about cancer, usually more than others, faced with cancer risk factors (Kurtuncu et al., 2014). So, it achieved through education, information seeking and using from educational material to enhance awareness of cancer symptoms and risk factors (Forbes et al., 2013; Al-Azri et al., 2014). Afterwards, improve the lifestyle and risk factors avoidance for example changing poor dietary habits, avoiding stress; smoking and alcohol drinking, maintaining normal physical and mental conditions and physical activity (Wang and Chung, 2012; Yilmaz et al., 2013). Third, self-awareness of physiological condition that means control of BMI; stress level; sleep quality and bowel or bladder habit and also attention to unusual and unexplained symptoms (Forbes et al., 2013; Heikkila et al., 2013). These strategies considered as self-care strategies in the primary prevention level that is preventing the occurrence of cancer. The fourth strategy is health screening and early detection that needs to awareness of qualified persons features for screening and encounter to screening services and tests existing for most cancers and self-examination for breast cancer. Unlike previous cases, this is placed in the secondary prevention level that is related to preventing of development of cancer in the body. Final group of self-care strategies, which is preventing recurrence of cancer in after healing, applied to avoidance of recurrent primary tumors to develop in survivors already cured for their malignant lesions. Follow up and commitment to caregiver recommendations and self-care tasks are its practices.

\section{Self-management strategies of cancer}

Studies showed that most advanced cancer patients complain of symptoms that can relieve by self-management practices, which are evidence-based and supervised by caregivers (Shoemaker et al., 2011; Walling et al., 2014). The relief of symptoms such as pain or fatigue, which are more common among cancer patients, will have a significant impact on patients' quality of life (Brant, 2010; Wang et al., 2014). Studies have depicted positive effect of direct education at patient for symptoms self-management and self-help practices in improving patients' ability in coping with the cancer or treatment related symptoms and consequents, and enhancing of the overall quality of life (Lee et al., 2014; Lovell et al., 2014). Self-help includes non-medical activities to enhance physical and psychological well-being (Foster et al., 2005). For instance, to attending in support groups (Sautier et al., 2014), to using complementary and alternative therapies such as yoga; massage therapy; acupuncture, meditation and so on for relieving stress and other cancer related symptoms(Edwards et al., 2014; Garcia et al., 2014; Smith et al., 2014), or to attending in self-help exercise programs for prevent some problems in some cancers (Cnossen et al., 2014)

\section{Portals for Cancer}

The portal is the infrastructural technology that integrates applications, services and information from a variety of sources in different networks the independent of time, format and place (Carbone and Burgess, 2009; Safdari and Azadmanjir, 2012). It provides secure, customizable, personalized access to dynamic content on a specific domain of interest and solves the problem of static and scattered high volume of information and services in different networks (Rovan et al., 2011; Safdari et al., 2012). In health, the portal is the integrating key agent of health information systems and applications in an electronic health environment (Edenius, 2009). It substantially has been developing on internet, extranet or intranet networks and called web-portal. Recently has been also possible the development of this technology on mobile networks (e.g. 2G, 3G) as mobile portals (Lee and Park, 2013). Due to the widespread use of mobile devices, mobile portals have more potential than the web portals in the field of health and care (Safdari and Azadmanjir, 2014). Because, The International Telecommunication Union (ITU) in May 2014 estimates that there are nearly 7 billion mobile subscriptions in the worldwide. It is equivalent to 95.5 percent of the world population. In Asia and Pacific, this rate has estimated $89.2 \%$ Per 100 people (Mobithinking, 2014). 
Anyway, in the field of chronic diseases such as cancer, portals whether web-based or mobile-based have great potential for improvement of self-care and self-management through facilitating communication, maximizing convenience, shared medical decision-making and so on (Ancker et al., 2011; Byczkowski et al., 2011; Britto et al., 2013). They can be developed for cancer in national level and help to behavior change of healthy people to cancer prevention or the daily management of cancer by patients. In previous studies stated the capabilities and specifications of web and mobile portals (Tatnall, 2005; Safdari et al., 2011; Safdari et al., 2012; Safdari and Azadmanjir, 2014). Therefore, here the authors explain only potentials of those capabilities on implement of self-care and self-management strategies for cancer.

\section{Cancer portal and self-care against cancer}

It is obvious that for public awareness about cancer, which defined as primary self-care strategy, should be used the proper media. Although still in association with cancer awareness, in some of the communities the usual and traditional media such as Television or print materials are more accessible than the internet or mobile (Nessa et al., 2013), but the number of internet users is not low. The numbers of people seeking cancer information on the internet are also significant (McHugh et al., 2011; Shahrokni et al., 2014). Recently, the positive impact of cancer related information in internet on cancer prevention behaviors and modifying lifestyle factors related to cancer have investigated (Richardson et al., 2013; Xavier et al., 2013). However, the most important issue is the quality of cancer information on the internet. Previous studies have demonstrated despite the numbers of health or cancerrelated websites have recently grown, the majority of them have not been accredited in terms of quality (Stinson et al., 2011; Lawrentschuk et al., 2012; Valero-Aguilera et al., 2014).

Cancer Portals through Content Management Systems (CMS) and knowledge management mechanisms can provide access to quality-controlled collection of cancerrelated content on the web. Also, cancer portals can be improved or be intelligent by machine learning techniques for quality assessment of cancer-related information resources (Xie and Burstein, 2011).

Personalization capability of portals helps to deliver content and services based on the user's needs and interests. For example a woman who has family history of breast cancer, after creating a profile in cancer portal, will receive information and services on the prevention of breast cancer or other cancers that are common in women. Moreover, cancer portals if be more user-sensitive or their CMS designed based on vector space models (VSM) (De Silva and Burstein, 2014), people can obtain their needed information more quickly. Electronic newsletters, that published through the portal, with topics such as new findings on cancers epidemiology, carcinogens, nutritional antioxidants and new diagnostic and treatment methods, will increase public awareness of the cancer. Educational materials or guidelines for cancer prevention and coping with risk factors can feed to the portal by authorities such as the department of health. Online educational programs can also be implemented in the portal through collaborative tools or forums. People can have customized access to these materials and programs so that they have access based on their needs, preferences and profile data that reflect their general health condition and behavior.

Capabilities of cancer portals for self-awareness of physiological condition are include embedded valid and reliable medical calculators for BMI, stress or even fat, carbohydrate and fiber intake and so on. Today, cancer risk check tools or calculators are available (Waters et al., 2009; Lundon et al., 2014) that can be implemented on the cancer portal. They are user-friendly and interactive, estimate the risk of cancer based on profile data and other data in few minutes, and then provide personalized tips for prevention, which are usually toward a healthier lifestyle.

In the portal, there are collaboration capabilities such as forums, chat rooms or virtual discussion groups (Tatnall, 2005) in which individuals can communicate and consult with specialists include oncologists for receive preventive recommendations to the public receiving high-risk people. People who are high-risk or concerned for cancer can have direct and privet communicate to physicians via portal email or online forms and get advice for coping with risk factors or early detection of cancer. People can find hospitals and medical diagnostic centers that perform screening tests through links on the portal.

\section{Cancer portal and self-management of cancer patients}

Access to patient health record (PHR), online check appointments to visit or chemotherapy session and possibility to send and receive messages to and from their care team by survivors, can be provided through the portal. The cancer portal can contribute using nonpharmacological approaches to symptom management for instance, to alleviate fatigue or pain related to chemotherapy or radiation. Verified symptom assessment tools with self-reported scales can be accessed through the portal and integrated to guidelines for patient. The guidelines recommend non-pharmacological options that have significant impact on symptom alleviation based on evidences. Tools for contributing to daily task management to conserving energy and reduce stress or services and capabilities such as listening to music; reading; gaming and taking that can be a distraction from the perception of pain, fatigue and other unpleasant symptoms can assist the patient in the management of symptoms (Borneman, 2013). In addition, in the portal can be provided multimedia training files for relaxation exercises, meditation or cognitive behavioral therapy that teaches patients to understand how thoughts can influence their feelings and behavior. Several clinical trials showed positive impact of these therapy options on self-management practices and patient quality of life (Loh et al., 2011b; Mahigir et al., 2012; Savard et al., 2014).

In conclusion, successful promoting of self-care and self-management strategies need to people and patients empowerment. If portals specialized in cancer prevention and care, they play an important role in the empowerment process. Although medical centers and hospitals can implement portal for their cancer patients, but due to needing to strong infrastructure and careful 
quality supervision on services and content, in particular about the reliability and validity of medical assessment and measurement tools, it is better that cancer patient portals implemented by the institute for cancer control and prevention in each country.

\section{References}

Ageing AGDoHa (2009). Capabilities for Supporting Prevention and Chronic Condition Self-Management: A Resource for Educators of Primary Health Care Professionals. Flinders University, Australia, 6.

Al-Azri M, Al-Rasbi K, Al-Hinai M, et al (2014). Awareness of risk factors for cancer among Omani adults - a community based study. Asian Pac J Cancer Prev, 15, 5401.

Ancker JS, Barrón Y, Rockoff ML, et al (2011). Use of an electronic patient portal among disadvantaged populations. J General Int Med, 26, 1117-23.

Barlow J, Wright C, Sheasby J, et al (2002). Self-management approaches for people with chronic conditions: a review. Patient education and counseling, 48, 177-87.

Benson JR, Jatoi I (2012). The global breast cancer burden. Future Oncology, 8, 697-702.

Borneman T (2013). Assessment and management of cancerrelated fatigue. J Hospice Palliative Nursing, 15, 77-86.

Brant JM (2010). The global experience of cancer pain. Asian Pac J Cancer Prev, 11, 7-12.

Britto MT, Hesse EA, Kamdar OJ, et al (2013). Parents' perceptions of a patient portal for managing their child's chronic illness. J Pediatrics, 163, 280-1.

Byczkowski TL, Munafo JK, Britto MT (2011). Variation in use of Internet-based patient portals by parents of children with chronic disease. Arch Pediatr Adolesc Med, 165, 405-11.

Carbone D, Burgess S (2009). Health portals: An exploratory review. In 'Medical Informatics: Concepts, Methodologies, Tools, and Applications', Eds medical information science reference, Hershey, New York, 58-61

Cleeland CS, Zhao F, Chang VT, et al (2013). The symptom burden of cancer: Evidence for a core set of cancer-related and treatment-related symptoms from the eastern cooperative oncology group symptom outcomes and practice patterns study. Cancer, 119, 4333-40.

Cnossen IC, van Uden-Kraan CF, Rinkel RN, et al (2014). Multimodal guided self-help exercise program to prevent speech, swallowing, and shoulder problems among head and neck cancer patients: a feasibility study. J Med Int Res, 16.

De Silva D, Burstein F (2014). An intelligent content discovery technique for health portal content management. JMIR Med Informatics, 2, 1-7.

Edenius M (2009). Empowerment and health portals. in 'medical informatics: concepts, methodologies, tools, and applications', eds medical information science reference, Hershey, New York, 1567.

Edwards GV, Aherne NJ, Horsley PJ, et al (2014). Prevalence of complementary and alternative therapy use by cancer patients undergoing radiation therapy. Asia Pac J Clin Oncol, 10, 346-53.

Forbes L, Simon A, Warburton F, et al (2013). Differences in cancer awareness and beliefs between Australia, Canada, Denmark, Norway, Sweden and the UK (the International Cancer Benchmarking Partnership): do they contribute to differences in cancer survival\&quest. Br J Cancer, 108, 292-300.

Foster C, Hopkinson J, Hill H, et al (2005). Supporting self management of people affected by cancer: a review of the evidence. University of Southampton, 25-30.
Garcia MK, McQuade J, Lee R, et al (2014). Acupuncture for Symptom Management in Cancer Care: an Update. Current oncology reports, 16, 1-9.

GLOBOCAN. 2014a. All cancers excl. non-melanoma skin cancer - Estimated incidence and prevalence, adult population: both sexes [Online]. International Agency for Research on Cancer (IARC). Available: http://globocan.iarc. fr/Pages/online.aspx [Accessed 27 Oct 2014].

GLOBOCAN. 2014b. Prevalence/incidence, pie chart: cancers by population [Online]. IARC. Available: http://globocan. iarc.fr/Pages/pie_pop_prev_sel.aspx [Accessed 29 Oct 2014].

Grady PA, Gough LL (2014). Self-Management: A Comprehensive Approach to Management of Chronic Conditions. Am J Public health, 104, 25-31.

Heikkilä K, Nyberg ST, Theorell T, et al (2013). Work stress and risk of cancer: meta-analysis of 5700 incident cancer events in 116000 European men and women. BMJ, 346.

Hewitt M, Greenfield S, Stovall E (2005). From cancer patient to cancer survivor: lost in transition. Institute Of Medicine and National Research Council of the National Academies, Washington, D.C, 506.

IARC (2013). Latest world cancer statistics. Int Agency Res Cancer (IARC), 1-3.

Jung M (2013). Cancer Control and the Communication Innovation in South Korea: Implications for Cancer Disparities. Asian Pac J Cancer Prev, 14, 3411-7.

Kurtuncu M, Akhan LU, Celik S, et al (2014). Cancer awareness among university students in Turkey. Asian Pac J Cancer Prev, 15, 4289.

Lawrentschuk N, Sasges D, Tasevski R, et al (2012). Oncology health information quality on the internet: a multilingual evaluation. Ann Surgical Oncol, 19, 706-13.

Lee J, Park MC (2013). Factors affecting the smartphone users to use the mobile portal services: focusing on Korean mobile portals. Information Systems e-Business Management, 11, 235-52.

Lee YJ, Hyun MK, Jung YJ, et al (2014). Effectiveness of education interventions for the management of cancer pain: a systematic review. Asian Pac J Cancer Prev, 15, 4787-93.

Loh S, Ong L, Ng LL, et al (2011a). Qualitative experiences of breast cancer survivors on a self-management intervention: 2 year post-intervention. Asian Pac J Cancer Prev, 12, 1489-95.

Loh S, Yip C, Packer T, et al (2010). Self management pilot study on women with breast cancer: lessons learnt in Malaysia. Asian Pac J Cancer Prev, 11, 1293-9.

Loh SY, Chew SL, Lee SY, et al (2011b). Quality of life in breast cancer survivors: 2 years post self-management intervention. Asian Pac J Cancer Prev, 12, 1497-501.

Loh SY, Chew S (2011). Awareness and practice of breast self examination among Malaysian women with breast cancer. Asian Pac J Cancer Prev, 12, 199-202.

Lovell MR, Luckett T, Boyle FM, et al (2014). Patient education, coaching, and self-management for cancer pain. J Clin Oncol, 32, 1712-20.

Lundon D, Kelly B, Foley R, et al (2014). Prostate cancer risk assessment tools in an unscreened population. World $J$ Urol, 1, 6 .

Mahigir F, Khanehkeshi A, Karimi A (2012). Psychological treatment for pain among cancer patients by rational-emotive behavior therapy-efficacy in both India and Iran. Asian Pac J Cancer Prev, 13, 4561-5.

McCorkle R, Ercolano E, Lazenby M, et al (2011). Selfmanagement: enabling and empowering patients living with cancer as a chronic illness. CA Cancer J Clin, 61, 50-62.

McHugh S, Corrigan M, Morney N, et al (2011). A Quantitative 
From Self-care for Healthy People to Self-management for Cancer Patients with Cancer Portals

assessment of changing trends in internet usage for cancer information. World J Surgery, 35, 253-7.

Mobithinking. 2014. Global mobile statistics 2014 Part A: Mobile subscribers; handset market share; mobile operators [Online].Available: http://mobiforge.com/research-analysis/ global-mobile-statistics-2014-part-a-mobile-subscribershandset-market-share-mobile-operators [Accessed 14 Nov 2014].

Nessa A, Hussain MA, Rashid M, et al (2013). Role of print and audiovisual media in cervical cancer prevention in Bangladesh. Asian Pac J Cancer Prev, 14, 3131-7.

Oluka OC, Shi YY, Nie S-F, et al (2014). Boosting cancer survival in nigeria: self-management strategies. Asian Pac J Cancer Prev, 15, 335-41.

Richardson C, Hamadani L, Gotay C (2013). Quantifying canadians' use of the internet as a source of information on behavioural risk factor modifications related to cancer prevention. Chronic Dis Inj Can, 33, 123-8.

Rovan L, Jagust T, Baranovic M (2011). Defining categories and functionalities of semantic web applications. Int J Systems Applications Engineering Development, 245-53.

Safdari R, Azadmanjir Z (2012). Application of Portal in Health. In 'Introduction to Nursing Informatics', Eds Jafari Publisher, Tehran, Iran, 51-67

Safdari R, Azadmanjir Z (2014). Mobile Health Protals in E-Health. Lecture in $2^{\text {ed }}$ Conference on Telemedicine. Amirkabir University of Technology 2014, Tehran, Iran.

Safdari R, Masoori N, Torabi M, et al (2012). Nursing portal; a nursing informatics solution for iran, lessons learned from a Comparative Study. Nurs Inform, 2012, 341-5.

Safdari R, Torabi M, Cheraghi MA, et al (2011). Achievements of nursing portal development in selected countries. HAYAT, 17, 46-62.

Sautier L, Mehnert A, Höcker A, et al (2014). Participation in patient support groups among cancer survivors: do psychosocial and medical factors have an impact? European $J$ Cancer Care, 23, 140-8.

Shahrokni A, Mahmoudzadeh S, Lu BT (2014). In whom do cancer survivors trust online and offline? Asian Pac J Cancer Prev, 15, 6171

Shoemaker LK, Estfan B, Induru R, et al (2011). Symptom management: an important part of cancer care. Cleveland Clin J Med, 78, 25-34.

Skerman HM, Yates PM, Battistutta D (2012). Cancer-related symptom clusters for symptom management in outpatients after commencing adjuvant chemotherapy, at 6 months, and 12 months. Supportive Care Cancer, 20, 95-105.

Smith PJ, Clavarino A, Long J, et al (2014). Why do some cancer patients receiving chemotherapy choose to take complementary and alternative medicines and what are the risks? Asia Pac J Clin Oncol, 10, 1-10.

Spinks TE, Ganz PA, Sledge Jr GW, et al (2014). Delivering highquality cancer care: the critical role of quality measurement. Healthcare, 2, 53-62.

Stinson JN, White M, Breakey V, et al (2011). Perspectives on quality and content of information on the internet for adolescents with cancer. Pediatric Blood Cancer, 57, 97-104.

Tatnall A (2005). Web portals : the New Gateways to Internet Information and Services, Hershey PA, Idea Group Publishing.

Valero-Aguilera B, Bermudez-Tamayo C, Garcia-Gutierrez J, et al (2014). Information needs and Internet use in urological and breast cancer patients. Supportive Care in Cancer, 22, 545-52.

Walling AM, Weeks JC, Kahn KL, et al (2014). Symptom prevalence in lung and colorectal cancer patients. $J$ Pain Symptom Management, (in Press).
Wang H-H, Chung U-L (2012). Healthy lifestyle changes during the period before and after cancer diagnosis among breast cancer survivors. Asian Pac J Cancer Prev, 13, 4769-72.

Wang XS, Zhao F, Fisch MJ, et al (2014). Prevalence and characteristics of moderate to severe fatigue: A multicenter study in cancer patients and survivors. Cancer, 120, 425-32.

Waters EA, Sullivan HW, Nelson W, et al (2009). What is my cancer risk? how internet-based cancer risk assessment tools communicate individualized risk estimates to the public: content analysis. J Med Int Res, 11.

Webber D, Guo Z, Mann S (2013). Self-care in health: we can define it, but should we also measure it? Self Care J, 4, 101-6.

WHO (2009). Self-care in the context of primary health care. regional office for south-east Asia. World Health Organization, 17.

Xavier AJ, d'Orsi E, Wardle J, et al (2013). Internet Use and Cancer-Preventive Behaviors in Older Adults: Findings from a Longitudinal Cohort Study. Cancer Epidemiol Biomarkers Prev, 22, 2066-74.

Xie J, Burstein F (2011). Using machine learning to support resource quality assessment: an adaptive attribute-based approach for health information portals. in 'database systems for adanced applications', Eds Springer, 526-37

Yilmaz M, Sanli D, Ucgun M, et al (2013). Lifestyle behaviors and early diagnosis practices of cancer patients. Asian Pac J Cancer Prev, 14, 3269-74.

Yoo B-N, Choi KS, Jung K-W, et al (2012). Awareness and practice of breast self-examination among Korean women: results from a nationwide survey. Asian Pac J Cancer Prev, 13, 123-5.

Yoo K-Y (2010). Cancer prevention in the Asia Pacific region. Asian Pac J Cancer Prev, 11, 839-44. 